Our major concern is of course the impact of low funding on the quality of care which we can offer our patients. Junior doctors are particularly well placed to monitor the effects of reduced facilities on in-patients, particularly in long-term wards. It is important that details of difficulties are given as accurately as possible and the information will be passed on to the DHSS as part of the College's campaign to protect and develop psychiatric services. The information could be given to me directly or through the local CTC representative whose name will be available from Mrs Jean Wales at the College.

PETER RICE

Chairman

Collegiate Trainees' Committee

\section{Is there a role for community clinical medical Dear SiRS officers in mental handicap?}

In his letter to the Bulletin (March 1988), Dr D. A. Spencer posed the question whether there is a need to create a new post of community medical officer for mentally handicapped adults. In my opinion, the answer is an emphatic 'No'. The integration of medically handicapped people is difficult enough; there is no need to make it more difficult by creating a new category of medical posts and depriving them of normal services which are available to other groups of the population. In fact, the surveys by Beckitt, Searle \& Wright" conclude: "The primary care of people with mental handicap living in an institution but due for community resettlement soon, could well be met by family doctors. People with mental handicap do not make significantly greater demands on primary medical care services than other people of the same age groups, nor is the pattern of their consultations different in terms of urgency, venue, nature or timing."

Discharging a large number of mentally handicapped people from hospitals into the list of one GP does not helpif the patients are spread over a large area involving the practice of all the GPs in a district, the GPs as well as members of the community respond with much more interest and enthusiasm. Of course, every GP should be consulted before sending patients to him or her. Support by core members of the Community Handicap Team (e.g. community nurses and social workers) is a great help to the mentally handicapped people and the GPs.

I would reiterate ${ }^{2}$ " ... the initiative of disengaging from non-psychiatric problems and making other specialists and general practitioners interested and involved in the problems of the mentally handicapped must come from psychiatrists in mental handicap. Surely, there is no need for 'new doctors' but there is a need for better use of existing doctors of all disciplines."

Windsor Unit

D. Chakraborti

King's Lynn, Norfolk
REFERENCES

${ }^{1}$ Beckitt, D., Searle, G. F. \& Wright, E. C. (1987) What sort of doctors do people with mental handicap need? British Journal of Clinical \& Social Psychiatry, 5, 38-42.

${ }^{2}$ ChAKRABORTI, D. (1987) Consultant psychiatrist in mental handicap. Bulletin of the Royal College of Psychiatrists, 11, 132.

\section{Does Hollywood need the MRCPsych? \\ DeAR SiRS}

Psychiatrists have usually been portrayed in the cinema as tolerant, patient and paternal. Having seen 'The House of Games', a recent success in Britain and America, we are irritated that a new cliché has been created.

The leading character in this film is a female psychiatrist. She is unemotional, highly successful, but with a life so devoid of excitement that she must enter the world of her patient to be fully satisfied. Dr Margaret Ford (Lindsay Crouse) wears expensive but boring clothes and speaks in a precise clipped fashion: only glaringly obvious Freudian slips indicate that there is a beating heart below the surface. The author of a book called Driven (supposedly about addictions), she sees patients on an individual basis in a large State Hospital. Her only friend is a large German psychoanalyst (the matriarchal version of the old cliche, perhaps?) who helpfully interprets Dr Ford's frequent parapraxes.

Dr Ford is seeing a gambler for individual psychotherapy. Despite her years of experience, she commits two cardinal sins of such treatment-collusion and over-involvement. She believes her patient's threat of suicide (because he owes a large amount of money) and agrees to help him financially.

She is drawn into the dark mysterious world of expert conmen. With her initial false moves, we are not surprised to find that, at the end, she has been the victim of a huge conjob. When she turns to petty theft, she merely confirms our suspicions that she was not cut out to be a psychiatrist after all. Indeed her continuously flattened affect might lead us to question her mental stability.

In an effort to create an interesting character, David Mamet has tried too hard. We found ourselves wishing for the melodrama of psychiatry of less 'realistic' films, rather than this contrived female psychiatrist.

So it is only cinema? This is merely irritating. American film-directors need to take a closer look at their psychiatrists, and indeed, at their women. Will the MRCPsych become a necessary qualification in Hollywood? Perhaps it should be bestowed honorarily on those directors and actors who portray our profession with credibility!

AIsLing CAMpbell

RAYMOND TRAVERS EAMONN MOLONEY

National Drug Advisory and Treatment Centre,

Jervis Street, Dublin I 